\title{
Cuidar de pessoa incapacitada por acidente vascular cerebral no domicílio: o fazer do cuidador familiar*
}

\author{
EL CUIDADO DE LA PERSONA INCAPACITADA POR ACCIDENTE CEREBRO \\ VASCULAR EN EL DOMICILIO: EL HACER DEL CUIDADOR FAMILIAR
}

Nara Marilene Oliveira Girardon Perlini' ${ }^{1}$, Ana Cristina Mancussi e Faro²

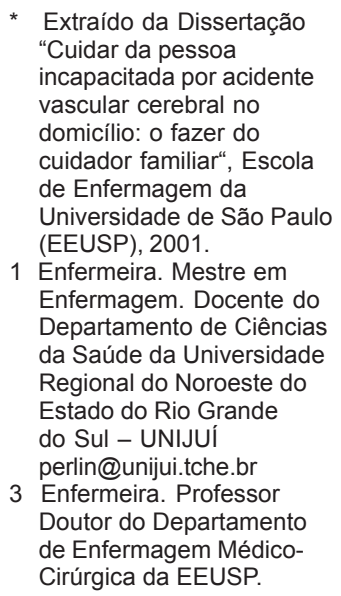

1 Enfermeira. Mestre em Enfermagem. Docente do Departamento de Ciências da Saúde da Universidade Regional do Noroeste do Estado do Rio Grande do Sul - UNIJUí perlin@unijui.tche.br

3 Enfermeira. Professor Doutor do Departamento de Enfermagem MédicoCirúrgica da EEUSP.

\begin{abstract}
RESUMO
Estudo exploratório, descritivo e quantitativo que busca identificar e descrever as atividades do familiar que cuida de pessoas incapacitadas por AVC no domicílio. A amostra constituiuse de 35 cuidadores familiares, predominantemente mulheres, esposas ou filhas. Os cuidados realizados relacionam-se ao grau de incapacidade do familiar. As orientações recebidas denotam falta de compromisso dos profissionais com a continuidade do cuidado. $O$ cuidador aprende a cuidar no cotidiano, com base na observação e auxílio à enfermagem na internação. As dificuldades pautam-se no esforço físico, na desinformação e no medo, no constrangimento e na vergonha em lidar com o corpo do outro. O estudo enfoca a necessidade do preparo para a alta hospitalar, salienta a família como espaço concreto para o cuidado; o aumento da expectativa de vida é uma constatação.
\end{abstract}

\section{DESCRITORES}

Cuidadores.

Cuidados domiciliários de saúde. Acidente cerebrovascular.

\section{ABSTRACT}

An exploratory descriptive and quantitative study aimed at identifying and describing the activity of relatives in charge of caring at home for people incapacitated by cerebral vascular accident. The sample was comprised of 35 family caregivers, most of them women, wives or daughters. The care given is directly related to the degree of incapacity of the person who is being cared for. The orientation received indicated no commitment of professionals for the continuity of the care. The caregivers learn in daily practice how to care, based on observation and assistance to nursing during the internment period. The difficulties are related to physical effort, to lack of information and fear, to the embarassment and the shame of handling someone else's body. The study focuses on the need for preparation for hospital discharge, emphasizes the family as a concrete space for care; and observed an increase in life expectancy.

\section{KEY WORDS}

Caregivers.

Home nursing.

Cerebral vascular accident.

\section{RESUMEN}

Estudio exploratorio, descriptivo y cuantitativo que busca identificar y describir las actividades del familiar que cuida de personas incapacitadas por ACV en el domicilio. La muestra estuvo constituida de 35 cuidadores familiares, predominantemente mujeres, esposas o hijas. Los cuidados realizados se relacionan con el grado de incapacidad del familiar. Las orientaciones recibidas denotan falta de compromiso de los profesionales con la continuidad del cuidado. El cuidador aprende a cuidar en el cotidiano, con base en la observación y el auxilio prestado a enfermería durante el internamiento. Las dificultades se pautan en el esfuerzo físico, en la desinformación y en el miedo, en el recelo y en la vergüenza para lidiar con el cuerpo del otro. El estudio enfoca la necesidad de preparación para la alta hospitalaria y resalta la familia como espacio concreto para el cuidado; el aumento de la expectativa de vida es una constatación.

\section{DESCRIPTORES}

Cuidadores.

Cuidados domiciliarios de salud. Accidente cerebro vascular.

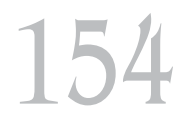




\section{INTRODUÇÃO}

A perspectiva de aumento acentuado da longevidade que ocorre nos países em desenvolvimento tem determinado uma mudança no perfil demográfico de todo o mundo e não apenas nos países europeus. Desde a década de 60, evidencia-se no Brasil, um aumento das doenças crônico-degenerativas, principalmente as afecções cardiovasculares, suplantando as enfermidades infecciosas e parasitárias como causa de morte ${ }^{(1)}$.

Dentre as doenças crônico-degenerativas, as cerebrovasculares constituem a terceira causa de morte no mundo, precedida pelas cardiopatias em geral e o câncer. OAcidente Vascular Cerebral (AVC) - isquêmico ou hemorrágico, transitório ou definitivo - é a doença cerebrovascular que apresenta maior incidência, tem maior morbidade e resulta em incapacidades ${ }^{(2-3)}$.

Cerca de 40 a $50 \%$ dos indivíduos que sofrem AVC morrem após seis meses. A maioria dos sobreviventes exibirá deficiências neurológicas e incapacidades residuais significativas, o que faz desta patologia a primeira causa de incapacitação funcional no mundo ocidental ${ }^{(4)}$.

Embora os dados epidemiológicos mostrem um declínio da mortalidade, é de se esperar que a incidência da doença reverta num quadro de prevalência de deficiências físicas e mentais relacionadas aos episódios de derrame cerebral ${ }^{(3)}$. Enfatizam, ainda, que há dados suficientes para afirmar que o AVC é uma doença grave no Brasil, geradora de incapacidades crônicas, com perda da independência e, muitas vezes, da autonomia, o que pressupõe a necessidade de alguém que auxilie o paciente nas suas dificuldades de desempenho das atividades diárias ${ }^{(3)}$.

Convém salientar que programas de reabilitação têm contribuído significativamente para diminuir os danos causados pela doença; porém, para que o êxito seja alcançado, é fundamental que se inicie, o mais cedo possível, medidas de reabilitação como forma de garantir uma recuperação eficaz. A reabilitação deve ser iniciada assim que o quadro clínico estabilizar ${ }^{(5)}$.

Todavia, a permanência de seqüelas incapacitantes, impondo aos pacientes limitações motoras, sensitivas, sensoriais, de compreensão e expressão dos pensamentos pode alterar a dinâmica da vida dessas pessoas, não só pelas seqüelas físicas que restringem as atividades da vida diária e tornam-nas, muitas vezes, dependentes de terceiros para movimentar-se e agir com maior ou menor independência, mas também por comprometerem suas possibilidades de administrar a vida pessoal e familiar ${ }^{(6)}$. Assim, pode-se afirmar que o AVC é uma doença crônica que causa incapacidade, deficiências e desvantagens.

Esta situação pode constituir-se numa fonte de tensão intrafamiliar. A necessidade de redefinição de papéis entre os membros da família, a "escolha" de alguém para assumir a responsabilidade dos cuidados e, em muitas vezes, a adequação do ambiente visando atender as demandas do familiar doente que retorna ao lar podem causar um impacto econômico e social que alteram a estrutura familiar. Porém, estudos revelam que a família é a fonte mais comum de apoio e cuidados, tanto para o suporte formal como para as tarefas mais específicas de ajuda, e somente quando esgotam os recursos é que esta procura o caminho da institucionalização ${ }^{(7)}$.

A experiência de cuidar de alguém acometido por AVC em casa tem se tornado cada vez mais freqüente no cotidiano das famílias. Nos hospitais, a política de incentivo à alta dos pacientes o mais cedo possível impõe um desafio constante às enfermeiras: preparar pacientes e famílias para reorganizarem a vida em seus lares de modo que possam assumir os cuidados próprios ou de familiares em poucos dias, detectando, prevenindo e controlando situações que possam ocorrer. Afinal, a fase final da recuperação irá acontecer no domicílio.

Para alguns autores é consenso ${ }^{(3,7)}$ que os cuidadores familiares recebem escassa orientação por parte dos profissionais a respeito dos cuidados com a saúde, entre esses, os necessários a idosos acometidos de AVC. No entanto, estes estudos permitem supor que, embora com falta de informações, os cuidadores cuidam de seus familiares doentes, mesmo que de uma forma intuitiva, com base em suas crenças, possíveis experiências anteriores, bem como pela troca de informações com outras pessoas, amigos, vizinhos, grupos ligados à igreja, grupos de voluntários, enfim, a rede de suporte social.

O conhecimento das atividades de cuidado desenvolvidas no domicílio e das dificuldades enfrentadas pelos cuidadores familiares de pacientes incapacitados por AVC poderá contribuir para as atividades educacionais da enfermagem e da equipe interdisciplinar, para que desenvolvam ações de preparo para a alta hospitalar, de acompanhamento domiciliário e de atenção ao cuidador a partir de dados que respondam às necessida-
Cuidar da pessoa incapacitada por acidente vascular cerebral no domicílio: o fazer do cuidador familiar 
Nara Marilene O. G. Perlini Ana Cristina M. e Faro des dos cuidadores e dos pacientes acometidos de AVC. Diante do exposto, o presente estudo tem como objetivo:

- Identificar e descrever as atividades do cuidador familiar que cuida de pessoas incapacitadas por acidente vascular cerebral no domicílio, conhecendo as dificuldades enfrentadas no seu cotidiano.

\section{CASUÍSTICA E MÉTODO}

A pesquisa foi do tipo exploratória, descritiva e transversal, numa abordagem quantitativa. Os sujeitos do estudo foram 35 cuidadores familiares principais de pessoas incapacitadas por AVC, residentes na zona urbana do município de Ijuí/RS. Foi considerado como cuidador familiar principal aquele que tem total ou maior responsabilidade pelos cuidados prestados no domicílio.

Como instrumento para a coleta dos dados, foi utilizado uma Ficha para identificar os pacientes e localizar os potenciais cuidadores familiares, elaborada pela pesquisadora, em que se registrou, a partir dos prontuários dos pacientes, dados considerados de interesse para localização do paciente; e um Formulário para entrevista com o cuidador familiar principal de paciente acometido por AVC, composto por quatro partes. Na primeira parte, abordou-se questões referentes à caracterização do cuidador familiar e do paciente. A segunda parte identificou as "condições clínicas do paciente", com base na capacidade motora e na Escala de Resultados de Glasgow (ERG), através da qual identificou-se o grau de incapacidade apresentada $^{(8)}$. Considerou-se que o resultado dentro das categorias de incapacidade grave e estado de vida vegetativo forneceriam a real demanda para o estudo, uma vez que estes pacientes são "incapazes e dependentes". A terceira parte continha dados voltados à família do paciente, sua condição social e econômica. A quarta parte visava informações sobre o cuidado realizado pelo cui-dador familiar, contendo questões referentes aos cuidados prestados, às orientações e informações recebidas durante o período da internação hospitalar e quem orientou/informou. Os cuidados foram organizados nas seguintes categorias: higiene corporal e oral, cuidados com a pele, eliminações, alimentação e hidratação, medicação de uso domiciliar, sono e repouso, atividade física, lazer e acompanhamento aos serviços de saúde ${ }^{(9-10)}$. Para identifi- car as dificuldades encontradas na realização do cuidar, utilizou-se uma questão aberta.

A coleta dos dados foi realizada nos meses de julho a setembro de 1999, através de visitas domiciliárias aos 132 pacientes que estiveram internados, com diagnóstico de AVC, em um hospital de grande porte na cidade de Ijuí (RS), no período de janeiro de 1998 a agosto de 1999 , que atendiam aos critérios de não constar registro de óbito e de residir na zona urbana do município.

Dos endereços obtidos, 15,9\% (21) não foram localizados e 15,2\% (20) pacientes haviam falecido. Assim, a primeira parte do instrumento e a ERG foi aplicada com 91 (68,9\%) cuidadores. Destes, 54 (40,9\%) tiveram boa recuperação ou as seqüelas existentes não os impediam de serem independentes e 37 (28,0\%) apresentavam-se incapazes de se autocuidarem, necessitando assistência de outra pessoa em graus variáveis. Dois foram excluídos por encontrarem-se em tratamento psiquiátrico (retardo mental e esquizofrenia), que por si só já denotam dependência de cuidados. Então, a terceira e quarta parte do instrumento foram aplicadas somente aos cuidadores cujo resultado da ERG do paciente foi de incapacidade grave ou estado de vida vegetativo, ou seja, a 35 cuidadores.

O estudo foi analisado e aprovado pelo Comitê de Ética em Pesquisa da Escola de Enfermagem da Universidade de São Paulo (CEP/EEUSP), sendo observado as orientações da Resolução 196/96 do Conselho Nacional de Saúde, que trata das Diretrizes e Normas Regulamentadoras de Pesquisa Envolvendo Seres Humanos ${ }^{(11)}$.

O tratamento dos dados foi realizado através de procedimentos de estatística descritiva. As questões abertas foram categorizadas a partir do princípio de classificação, observando-se as características da exaustividade, exclusividade e objetividade e, posteriormente, quantificadas. Os dados foram tabulados e analisados eletronicamente, utilizando-se o EPI-INFO, versão 6.04, de janeiro de 1997 e são apresentados em tabelas simples com números absolutos e percentuais. 
Tabela 1- Perfil do cuidador familiar principal de paciente incapacitado por AVC. (Ijuí (RS), 1999)

\begin{tabular}{|c|c|c|}
\hline Variável & $\mathbf{n}^{\mathbf{o}}$ & $\%$ \\
\hline \multicolumn{3}{|l|}{ Idade (em anos) } \\
\hline $23-39$ & 10 & 28,6 \\
\hline $40-59$ & 19 & 54,3 \\
\hline $60-73$ & 6 & 17,1 \\
\hline Média & 47,3 & \\
\hline Desvio padrão & 13,32 & \\
\hline \multicolumn{3}{|l|}{ Sexo } \\
\hline Masculino & 8 & 22,9 \\
\hline Feminino & 27 & 77,1 \\
\hline \multicolumn{3}{|l|}{ Cor da pele } \\
\hline Branca & 23 & 65,7 \\
\hline Parda & 10 & 28,6 \\
\hline Preta & 2 & 5,7 \\
\hline \multicolumn{3}{|l|}{ Religião } \\
\hline Católica & 23 & 65,7 \\
\hline Evangélica & 8 & 22,9 \\
\hline Outras & 4 & 11,6 \\
\hline \multicolumn{3}{|l|}{ Estado Marital } \\
\hline Casado & 26 & 74,3 \\
\hline Solteiro/separado & 7 & 20,0 \\
\hline Viúvo & 2 & 5,7 \\
\hline \multicolumn{3}{|c|}{ Escolaridade (anos de estudo) } \\
\hline Sem instrução & 2 & 5,7 \\
\hline $1-4$ & 10 & 28,6 \\
\hline $5-8$ & 13 & 37,1 \\
\hline 9 ou mais & 10 & 28,6 \\
\hline \multicolumn{3}{|c|}{ Situação atual de Ocupação } \\
\hline Afazeres do lar & 17 & 48,6 \\
\hline Aposentado/pensionista & 3 & 8,6 \\
\hline Domésticas remuneradas & 3 & 8,6 \\
\hline Comércio & 2 & 5,7 \\
\hline Indústria metalúrgica & 2 & 5,7 \\
\hline Outros* & 8 & 22,9 \\
\hline TOTAL & 35 & 100,0 \\
\hline
\end{tabular}

* Foram diversas as profissões/ocupações citadas tais como psicóloga, telefonista, trabalhador na construção civil, no transporte rodoviário, na indústria do vestuário, agricultor, vendedor ambulante e biscateiro. 
Nara Marilene O. G. Perlini Ana Cristina M. e Faro

Tabela 2 - Distribuição dos cuidados executados pelo cuidador segundo a necessidade de ajuda do paciente. (Ijuí (RS), 1999)

\begin{tabular}{|c|c|c|c|c|c|c|}
\hline \multirow{2}{*}{ Cuidados } & \multicolumn{2}{|c|}{ Sim } & \multicolumn{2}{|c|}{ Não } & \multicolumn{2}{|c|}{ Total } \\
\hline & $\mathrm{n}^{\mathrm{o}}$ & $\%$ & $\mathrm{n}^{\mathrm{o}}$ & $\%$ & $\mathrm{n}^{\mathrm{o}}$ & $\%$ \\
\hline Higiene no leito & 8 & 25,8 & 23 & 74,2 & 31 & 100,0 \\
\hline Higiene no chuveiro & 19 & 61,3 & 12 & 38,7 & 31 & 100,0 \\
\hline Higiene íntima & 13 & 41,9 & 18 & 58,1 & 31 & 100,0 \\
\hline Higiene do cabelo & 22 & 71,0 & 9 & 29,0 & 31 & 100,0 \\
\hline Higiene oral & 22 & 71,0 & 12 & 35,3 & 34 & 100,0 \\
\hline Troca de roupa & 33 & 97,1 & 1 & 2,9 & 34 & 100,0 \\
\hline Prevenção úlcera decúbito & 13 & 41,9 & 18 & 58,1 & 34 & 100,0 \\
\hline Mudança de decúbito & 9 & 26,5 & 25 & 73,5 & 34 & 100,0 \\
\hline Cuidado com dermatites & 10 & 29,4 & 24 & 70,6 & 34 & 100,0 \\
\hline Curativos & 3 & 8,8 & 31 & 91,2 & 34 & 100,0 \\
\hline Auxílio para uso de sanitários & 15 & 51,4 & 19 & 48,6 & 35 & 100,0 \\
\hline Auxílio para uso de comadre & 11 & 32,4 & 23 & 67,6 & 34 & 100,0 \\
\hline Troca de fraldas & 9 & 26,5 & 25 & 73,5 & 34 & 100,0 \\
\hline Dispositivo coletor de urina & 2 & 5,9 & 32 & 94,1 & 34 & 100,0 \\
\hline Sonda vesical de demora & 1 & 2,9 & 33 & 97,1 & 34 & 100,0 \\
\hline Preparo da alimentação & 28 & 96,6 & 1 & 3,4 & 29 & 100,0 \\
\hline Auxilia na alimentação VO & 23 & 67,6 & 11 & 32,4 & 34 & 100,0 \\
\hline Administra alimentação SNG & 2 & 5,9 & 32 & 94,1 & 34 & 100,0 \\
\hline Administra medicação & 26 & 76,5 & 8 & 23,5 & 34 & 100,0 \\
\hline Controla horário da medicação & 28 & 82,4 & 6 & 17,6 & 34 & 100,0 \\
\hline Posiciona para dormir & 10 & 29,4 & 24 & 70,6 & 34 & 100,0 \\
\hline Previne queda & 13 & 38,2 & 21 & 61,8 & 34 & 100,0 \\
\hline Auxilia na deambulação & 23 & 67,6 & 11 & 32,4 & 34 & 100,0 \\
\hline Auxilia no uso de equipamentos & 7 & 20,6 & 27 & 79,4 & 34 & 100,0 \\
\hline Estimula exercícios físicos & 20 & 58,8 & 14 & 41,2 & 34 & 100,0 \\
\hline Estimula atividades de lazer & 16 & 45,7 & 19 & 54,3 & 35 & 100,0 \\
\hline Acompanha serviço fisioterapia & - & - & 34 & 100,0 & 34 & 100,0 \\
\hline Acompanha consultas médicas & 34 & 97,1 & 1 & 2,9 & 35 & 100,0 \\
\hline
\end{tabular}

Tabela 3. Dificuldades relatadas pelos cuidadores quanto aos cuidados realizados. ((Ijuí (RS), 1999)

\begin{tabular}{lcc}
\hline Dificuldades & $\mathbf{n}^{\mathbf{o}}$ & $\mathbf{\%}$ \\
\hline Movimentar o paciente & 9 & 22,5 \\
Constrangimento / vergonha & 7 & 17,5 \\
Medo que o paciente caia & 3 & 7,5 \\
Financeira & 2 & 5,0 \\
Saber se o que faz está certo & 2 & 5,0 \\
Em reorganizar a vida & 1 & 2,5 \\
Em dar conta de todo o & 1 & 2,5 \\
serviço & 1 & 2,5 \\
Entender o que o paciente & & \\
fala & 1 & 2,5 \\
Entender a doença e suas & 7 & 17,5 \\
complicações & 6 & 15,0 \\
Não tem dificuldades & & \\
Não responderam & & \\
\hline TOTAL & \multirow{40*}{*}{$\mathbf{1 0 0 , 0}$} \\
\hline
\end{tabular}

* Alguns cuidadores referiram mais de uma dificuldade.

\section{DISCUSSÃO}

Abstraindo-se o perfil do cuidador familiar principal de paciente incapacitado por AVC, pode-se afirmar, de acordo com a tabela 1, que eram predominantemente mulheres $(77,1 \%)$, filhas $(40,0 \%)$ ou esposas $(22,9 \%)$, brancas $(65,7 \%)$, casadas $(74,3 \%)$, católicas $(65,7 \%)$, com idade entre 40 e 59 anos (54,3\%), escolaridade em nível de $1^{\circ}$ grau $(37,1 \%)$, que não exerciam atividade fora do lar $(48,6 \%)$, nunca tinham cuidado de alguém doente antes $(68,6 \%)$, moravam junto com os pacientes $(82,9 \%)$ e os cuidavam, em média, há 18,8 meses.

Os pacientes eram do sexo feminino $(51,4 \%)$ e do sexo masculino $(48,6)$. A idade variou entre 40 e 87 anos, sendo que a média foi de 66,7 anos e o desvio padrão de 13,32. Em relação ao estado marital, eram casados $(57,1 \%)$ viúvos $(31,4 \%)$ e 
solteiros ou separados $(11,4 \%)$, aposentados, pensionistas ou recebendo auxílio saúde 29 (82,9\%), de afazeres do lar $5(14,3 \%)$ e um $(2,9 \%)$ que se encontra impossibilitado de trabalhar e não conseguiu preencher os requisitos para receber auxílio saúde. Aqueles que exerciam atividade profissional antes do AVC não mais tiveram condições de desempenhá-las, encontrando-se atualmente em benefício.

Em relação às condições clínicas do paciente, constatou-se que o tempo decorrido do primeiro episódio do AVC é de 1 a 84 meses, numa média de 21,8 meses. Dos 35 pacientes que apresentavam dependência, 3 incluíam-se na categoria estado vegetativo, pois se apresentavam não responsivos a comandos verbais, acamados e totalmente dependentes. Os demais 32 apresentavam-se na categoria incapacidade grave e tinham diferentes graus de dependência.

As atividades realizadas pelo cuidador familiar podem ser identificadas na Tabela 2, a qual apresenta os cuidados por eles realizados. Esta tabela procura mostrar os cuidados realizados pelos cuidadores durante a assistência a seus familiares. Os cuidados informados como realizados referemse aos executados pelos cuidadores, independente do nível de participação (auxílio ou realização) e os não realizados tratam-se daqueles executados pelo próprio paciente, quando este era capaz de fazê-lo, ou quando não se faziam necessários.

Convém esclarecer, ainda, que quando o paciente apresentava dependência para realização de algum cuidado e este não era realizado pelo cuidador principal e sim por uma pessoa contratada, optou-se por excluí-lo do total de cuidadores, pois se entende que ao incluí-los dentre os que não prestam o cuidado, porque o familiar não necessita ou é capaz de realizar sozinho, estar-se-ia mascarando os cuidados demandados por parte dos pacientes. Deste modo, quando na tabela 1 verifica-se um total menos que 35 , significa que o cuidado é realizado por outra pessoa que não o cuidador principal.

Neste estudo são elencadas várias atividades possíveis de serem realizadas pelos cuidadores familiares, sendo que estas podem necessitar de maior ou menor envolvimento por parte do cuidador de acordo com o nível de dependência de cada paciente. Os dados permitem, portanto, identificar a freqüência e as atividades realizadas, porém não refletem a dimensão de envolvimento exigido para a execução.

Nesse sentido, pesquisa realizada sobre o tipo de assistência prestada pelos cuidadores a pes- soas com dependência aponta que determinar as atividades realizadas e o grau de ajuda necessária (parcial ou total) não espelha a real situação do dia-a-dia enfrentada pelo cuidador ${ }^{(12)}$. Cita, como exemplo, o caso da realização da higiene corporal. Esta pode ser realizada no leito ou no chuveiro. A realização do banho no leito geralmente demanda a pessoa que o está realizando esforço físico, organização e intimidade, independente de o paciente ser totalmente dependente ou poder colaborar de alguma forma, enquanto que para o banho no chuveiro pode ser necessária a execução em si, a qual implica, todavia, menor desgaste que no leito, o auxílio com as partes do corpo mais difíceis ou apenas a supervisão. Assim, conceber que todas as atividades envolvem o mesmo nível de dificuldade pode descaracterizar o trabalho dos cuidadores.

Resguardadas estas considerações, identificou-se tarefas que são realizadas pela maioria dos cuidadores e aquelas que são pouco ou não são realizadas. Estes dados possibilitam ao enfermeiro traçar linhas de orientação e suporte para instruir o cuidado domiciliário.

A tarefa citada como realizada por praticamente todos os cuidadores $(97,1 \%)$ trata-se de acompanhar o doente às consultas médicas. Mesmo os cuidadores que não residem junto com o paciente e, portanto, não prestam o cuidado direto, são quem o acompanha ao médico. A consulta médica pode ser vista como um momento importante e de grande responsabilidade, pois tratará das perspectivas futuras da saúde do familiar. E, por detrás da condição clínica apresentada, também se evidenciam relações de poder e de saber. De um lado, o cuidador principal, que é quem está investido de poder no cuidado do doente (é quem decide o que deve ser feito e providencia para que seja feito) e de outro, o médico, que detém o conhecimento da doença e de seu tratamento. Então, parece compreensível que seja o cuidador principal que discuta e receba do médico as informações sobre as condições e condutas necessárias para cuidar, já que a responsabilidade de viabilizá-las cabe a ele.

Vestir o paciente ou auxiliá-lo a trocar de roupa foi uma atividade mencionada por $33(97,1 \%)$ dos cuidadores. Um dos déficits apresentados como complicações ao derrame cerebral é a disfunção motora e/ou sensorial que pode ser manifestada através das hemiplegias, hemiparesias ou parestesias. Estes déficits levam à diminuição ou perda da capacidade de movimentar voluntariamente os membros do lado oposto ao que ocorreu o dano cerebral ${ }^{(9)}$.
Cuidar da pessoa incapacitada por acidente vascular cerebral no domicílio: o fazer do cuidador familiar 
Nara Marilene O. G. Perlini Ana Cristina M. e Faro
Atividades como se vestir, despir, fechar botões, calçar meias, amarrar cadarços de sapatos exigem coordenação motora, destreza manual e necessitam de ambas as mãos para serem executadas. Na presença de déficit motor, o desenvolvimento da atividade estará comprometido, ou seja, conforme o grau de comprometimento, para alguns indivíduos, há tarefas impossíveis de serem executadas, mesmo após a realização de treinamento específico para readquirir habilidade $\operatorname{motora}^{(9)}$

O preparo da alimentação e o controle da medicação aparecem como realizados por 28 $(96,6 \%)$ dos cuidadores. Entende-se que a maioria dos cuidadores são mulheres e que preparar as refeições é uma atividade quase sempre desenvolvida por elas, principalmente quando não trabalham "fora de casa". Entretanto, neste estudo, verificou-se que alguns cuidadores masculinos também preparavam as refeições evidenciando ser uma atividade que exige responsabilidade (por isso não é delegada), além de constituir-se uma necessidade básica para a sobrevivência e uma expressão de cuidado. Por outro lado, percebe-se também que esta é a atividade mais desenvolvida por pessoas contratadas.

Os déficits cognitivos resultantes do derrame podem comprometer a capacidade da pessoa concentrar-se, diminuir o nível de atenção, ocasionar a perda da memória de curtos ou longos períodos ${ }^{(9)}$, o que pode resultar no esquecimento da dose, do horário e do medicamento a ser tomado. Esta pode ser uma explicação porque tantos cuidadores ocupam-se em controlar o horário das medicações e em administrar a medicação para o paciente $(82,4 \%)$. Os cuidadores referem que fazer isso os deixa mais tranqüilos quanto a erros que possam acontecer se o paciente tomar o remédio sozinho ou o fato de não o tomarem.

Auxiliar na deambulação é referido por 23 $(67,6 \%)$ dos cuidadores como sendo uma das atividades do seu cotidiano. Percebe-se que existe diferente envolvimento por parte dos cuidadores ao desenvolver essa atividade. Há pacientes que, para se locomoverem, necessitam apenas de amparo em determinadas situações e outros que dependem constantemente de alguém para movimentá-los, até mesmo de serem carregados nos braços.

Outra atividade realizada pelos cuidadores está relacionada a higienização. Estes referem que seus familiares apresentam dificuldades principalmente para lavar os cabelos, algumas partes do corpo e realizar higiene oral. Ao falarem sobre essas atividades alguns relataram não contar com chuveiro, o que torna o banho uma atividade mais difícil de ser executada sem ajuda, principalmente se o paciente é pouco colaborativo ou muito dependente. A não existência de um chuveiro, segundo eles, torna esta atividade mais penosa pela necessidade de propiciar um local adequado para realizá-la. Alguns referiram que utilizam uma mangueira para a higiene corporal e do cabelo, porém a realizam fora de casa, no quintal. No inverno esta situação é mais complicada ainda. Segundo eles, o "banho de bacia" não proporciona uma boa higienização.

Ao contrário do que possa parecer, o banho no chuveiro pode representar muito mais ônus para o cuidador, visto que a falta de cooperação e as alterações de comportamento de seus familiares, que se acentuam em situações de banho, toalete e vestir, gera muito mais angústia para os cuidadores $^{(12)}$.

Auxiliar no uso de sanitários foi outra atividade mencionada pelos cuidadores com freqüência. Na maioria das vezes esta ajuda está mais relacionada à dificuldade na deambulação do que nas eliminações propriamente ditas. De qualquer modo, independente do motivo, nas vezes que o paciente necessitar ir ao banheiro, necessitará de alguém para auxiliá-lo e isto será uma demanda a ser atendida pelo cuidador.

Constata-se que as atividades desenvolvidas estão relacionadas às condições dos pacientes. Quanto mais comprometida sua autonomia, maior são as demandas e a complexidade das atividades desenvolvidas pelo cuidador. "Quanto maior a dependência (do idoso - em seu estudo) maior a necessidade de envolvimento pessoal do cuidador"(12).

Chama a atenção o fato de nenhum dos cuidadores acompanhar seu parente a serviços de fisioterapia ou reabilitação. Essa situação explica-se pelo fato de existir, na cidade, somente um serviço que atende pelo SUS e ao qual é encaminhada toda a demanda desta e das demais áreas da saúde. Desse modo, o acesso torna-se bastante limitado, restringindo-se a poucas pessoas. Procurar serviços privados pode constituir-se em uma demanda onerosa para seus orçamentos.

A realização de exercícios físicos ativos e passivos ou estímulo para que o paciente os realizem foi manifestada por $20(58,8 \%)$ cuidadores, porém alguns mencionaram que os fazem "quan- 
do têm tempo" ou "quando lembram". Essas afirmativas podem suscitar várias interpretações. Uma delas é a falta de tempo por parte do cuidador. Considerando que muitos deles, além de cuidarem do seu familiar, trabalham fora e/ou tem filhos e/ou cuidam da casa, ou seja, têm outras atividades no seu cotidiano; a não realização dos exercícios pode ser influenciada verdadeiramente pela falta de tempo. Diante de uma atividade diária de trabalho exaustiva, priorizar o que fazer não é uma tarefa simples.

Somado a isso, há também de considerar-se que muitos cuidadores são pessoas idosas e até doentes. A realização destas atividades exige esforço físico por parte de quem as realiza e quanto mais dependente for o paciente, maior será o desgaste físico. As afirmativas podem denotar, inclusive, desinformação por parte dos cuidadores em relação à importância da realização de atividades físicas em casos de disfunção motora, não apenas como forma de restaurar a mobilidade, mas principalmente de evitar agravos maiores, tais como: atrofia muscular, espasticidade, disartrias e lesões de pele por permanecer muito tempo sentado ou deitado, aliviar a dor nos casos de síndrome ombro-mão, melhorar os movimentos e, a longo prazo, recuperar a função do membro incapacitado ${ }^{(9)}$.

A realização de atividades de reabilitação é uma forma do indivíduo enfrentar a doença crônica e de “assumir novos encargos"(13). Os exercícios fisioterápicos e/ou fonoaudiológicos são vistos pelo paciente e familiares como uma possibilidade, a curto prazo, de retorno "ao que era antes do AVC". Porém, por ser o progresso muito lento, muitas vezes, as dificuldades e a dor durante a realização dos exercícios frustram essas expectativas. A consciência dessa situação gera sentimentos de desânimo que associado a outras dificuldades, como de transporte e recursos financeiros, com o passar do tempo levam a uma diminuição na adesão ao tratamento e paciente e família vão gradativamente "abandonando" os exercícios ${ }^{(13)}$. Os cuidados relacionados à atividade física do seqüelado de AVC exigem tratamento prolongado e contínuo, em torno oito meses a um ano ${ }^{(9)}$.

Percebe-se então que, exceto em relação aos pacientes com seqüelas graves e, que por isso, demandam cuidados específicos, as tarefas nas quais os cuidadores têm maior envolvimento referem-se às atividades da vida diária, ou seja, aquelas que o paciente apresenta impossibilidade de realizar.

A literatura de enfermagem enfatiza a importância e a necessidade da participação e do incentivo ao paciente para participar do seu autocuidado, destacando que a família deve ser orientada para cooperar nesse sentido, permitindo ao paciente a tentativa de fazê-lo. Os medos e angústias por parte do paciente e, principalmente, a dificuldade em expressá-los abertamente fazem-no adotar uma atitude passiva diante dos cuidados recebidos. Os familiares, por sua vez, subestimam a capacidade do paciente e adotam comportamentos superprotetores ${ }^{(13)}$.

Em pesquisa onde se procurou identificar as atividades desempenhadas por cuidadores familiares junto à pacientes com lesão medular no domicílio, tendo encontrado atividades relativas à higiene corporal, ao vestir e despir, ao conforto e posicionamento, a alimentação, às eliminações urinária e fecal, ao lazer e recreação, as quais apresentam similaridade às atividades realizadas pelos cuidadores de pacientes sequelados por $\mathrm{AVC}^{(14)}$. Estes resultados, comparados com os do presente estudo, indicam que cuidar de uma pessoa incapacitada em casa, independente do fator determinante da incapacidade, tem aspectos semelhantes em relação às atividades desenvolvidas pelo cuidador. O que define as atividades do cuidador é o grau de incapacidade e não a patologia que a causa.

As dificuldades referidas pelos cuidadores familiares no seu cotidiano são apresentadas na Tabela 3. Considerando o total de cuidadores (35), observa-se que 22 cuidadores referem ter dificuldades para cuidar, o que representa $67,5 \%$ (27) das respostas. Os outros 13 cuidadores não responderam a essa pergunta ou referiram não ter nenhuma dificuldade em cuidar.

Atividades que necessitam de esforço físico certamente são as que causam maior dificuldade para o cuidador, como demonstram os dados da referida tabela. Para cuidar de um adulto dependente é necessário ter condicionamento físico capaz de dar conta de tarefas pesadas, como a locomoção e outras, além de recuperar-se rapidamente, por exemplo, de uma noite mal dormida ${ }^{(15)}$.

As dificuldades manifestadas pelos cuidadores não expressam apenas dificuldades específicas a atividades referentes ao cuidado. Na verdade, as dificuldades que se esperava ouvir como respostas foram muito superficiais, pois não envolvem a execução de atividades propriamente dita, ou seja, o desempenho de uma tarefa. As dificuldades mencionadas expressam questões muito mais subjetivas relacionadas à dinâmica familiar e aos sentimentos dos cuidadores.

Isto pode ser evidenciado quando uma cuidadora referiu a dificuldade encontrada em reestru-
Cuidar da pessoa incapacitada por acidente vascular cerebral no domicílio: o fazer do cuidador familiar 
Nara Marilene O. G. Perlini Ana Cristina M. e Faro turar os papéis familiares. Até seu marido adoecer ela era uma mulher que se dedicava à casa e a família. Após a doença do marido, precisou assumir o gerenciamento do orçamento doméstico e tomar decisões. Situação similar a esta também foi identificada em outra investigação ${ }^{(15)}$.

A subjetividade também se faz presente nos medos e no constrangimento/vergonha. Podese inferir que nem sempre o banho em si significa uma tarefa difícil. A verdadeira dificuldade está em romper com valores arraigados desde a infância do cuidador e que representam invadir a privacidade e a intimidade do outro, que é seu pai, mãe, sogro, e que até então, ver ou tocar estes corpos era totalmente não aceito como natural, ou seja, era proibido.

Ao analisar o cuidador durante as visitas domiciliárias para a aplicação do instrumento da pesquisa, a mesma autora pondera que essa situação proporcionava ao entrevistado um momento de reflexão sobre o seu cotidiano ${ }^{(15)}$. "Não é apenas o fazer que define a identidade do cuidador, mas a consciência da atividade de cuidar e o significado desta em sua vida. Este é um processo que não acontece de repente: a consciência só surge com o passar do tempo".

Assim, quando indagados sobre as dificuldades enfrentadas na realização dos cuidados, refletem além da simples pergunta e pensam exatamente sobre aquilo que para eles significa dificuldade. Passado o primeiro impacto de ter que cuidar em casa, muitas dificuldades ao realizar alguma atividade torna-se insignificante frente à falta de dinheiro para comprar remédios, alimentos, cadeira de rodas etc. Esta análise pode explicar porque vários cuidadores responderam que não têm dificuldade para realizar os cuidados. Afirmaram que tinham dificuldades no início, quando iniciaram a cuidar, mas agora já as superaram.

Por outro lado, as respostas denotam também o desconhecimento por parte dos cuidadores a respeito da patologia de modo geral, da evolução do quadro clínico e suas possíveis complicações e da forma mais adequada para realizar o cuidado. A afirmação de que entender a doença e suas complicações é uma dificuldade referendam a análise, principalmente se associada às expressões "saber se o que está fazendo é certo, o medo de que o paciente caia e até movimentar o paciente". Se o cuidador tivesse ciência sobre as possíveis formas de atender as necessidades da pessoa sob sua responsabilidade e/ou conhecimento sobre a doença, ele poderia sentir-se mais seguro e confiante quanto ao seu desempenho e as respostas do paciente. Dúvidas e dilemas continuariam existindo, porém poderiam não gerar tanta ansiedade.

Neste contexto, pode-se deduzir que as informações/orientações fornecidas a esses cuidadores não foram suficientes para possibilitar-lhes uma ação segura, talvez possam até ter contribuído para mais temores. Isto é possível quando as orientações enfatizam a atenção que deve ser dispensada ao paciente com hemiplegia, por exemplo, pois ele pode cair e fazer uma fratura, ou a movimentação inadequada pode ocasionar uma luxação, etc. Muitas vezes, as orientações incompletas, que se limitam aos "alertas", incutem mais temor e insegurança do que servem de indicativo de ação.

O despreparo do cuidador pode trazer sérios prejuízos ao paciente, resultando, inclusive em freqüentes hospitalizações. Além disso, o despreparo pode gerar ansiedade e maior desgaste físico, ocasionando situações de risco para $\operatorname{ambos}^{(16-17)}$.

Uma das formas de ajuda às famílias em seu processo de cuidar é aquela advinda dos profissionais, que incluem orientações básicas à saúde, e sobre cuidados específicos em casos de doenças crônicas degenerativas, suas complicações e sintomas. Porém, há de se considerar que, muitas vezes, as orientações fornecidas são incoerentes e até impossíveis de serem realizadas no domicílio, em função das condições em que vivem $^{(18)}$. A principal ajuda constitui-se em colaborar para que o paciente e sua família alcancem a independência e possam administrar os cuidados necessários à situação vivida ${ }^{(19)}$.

\section{CONSIDERAÇÕES FINAIS}

Os fatores conjunturais, os estudos epidemiológicos e as pesquisas que abordam o cuidar/ cuidado domiciliário mostram que cuidar de doentes em casa não é mais uma tendência, é uma realidade. O cuidado informal é, e continuará sendo realizado por membros da família, na maioria dos casos, e em situações que englobam condições crônicas, de dependência a curto, médio e longo prazo, com uso ou não de aparato tecnológico. Compreender parte do processo de cuidar no domicílio possibilitou identificar algumas das carências e fragilidade para as quais o enfermeiro pode dirigir sua atenção, elegendo prioridades e concentrando seu trabalho.

Para que seja possível a continuidade do cuidado em casa, os cuidadores necessitam iniciar, 
ainda durante a hospitalização, a desenvolver a capacidade para cuidar. Isso significa a realização de um efetivo preparo para a alta hospitalar, onde o enfermeiro esteja verdadeiramente comprometido com esse propósito e esclareça as possíveis dependências do paciente e os cuidados iniciais que a família terá que tomar para si, assumindo com ela uma relação de cooperação e apoio. Como a recuperação do paciente está diretamente relacionada ao início de um programa de reabilitação precoce e aos cuidados para prevenir deformidades, a equipe de enfermagem, especialmente o enfermeiro, deve estar preparada para realizar esses cuidados e estimular o próprio paciente e os familiares a realizá-los de forma correta. O domicílio é uma área em que o enfermeiro também pode continuar colaborando. Assim, assistência domiciliária constituise numa metodologia de trabalho a ser redescoberta e melhor explorada pelos profissionais.
Os enfermeiros precisam ter claro que o processo saúde - doença não se limita aos espaços dos hospitais e dos postos de saúde, assim como o seu fazer e, por isso, interagir com as pessoas em seus domicílios é um desafio que necessita ser de fato assumido.

A guisa de conclusões pode-se afirmar que, pelo presente estudo, constata-se o aumento na expectativa de vida dos brasileiros como uma realidade e, em decorrência de viver mais, há aumento das doenças crônico-degenarativas que impõe novas demandas às famílias. Nesta perspectiva, salienta-se que esta se constitui em um espaço real para o cuidado, e para que possa desempenhar este papel de forma adequada, faz-se necessário que, em casos de internação, os possíveis cuidadores sejam desde cedo orientados. Deste modo, a necessidade do preparo para a alta hospitalar como uma importante ferramenta para os cuidados em casa.

\section{REFERÊNCIAS}

(1) Papaléo Neto M. Gerontologia. São Paulo: Atheneu; 1996.

(2) Barros JEF. Acidente vascular cerebral. In: Nitrini R, Bacheschi LA. A neurologia que todo médico deve saber. São Paulo: Maltese; 1991. p. 133-47.

(3) Karch UMS, organizador. Envelhecimento com dependência: revelando cuidadores. São Paulo: EDUC; 1998.

(4) André C. Manual de AVC. Rio de Janeiro: Revinter; 1999.

(5) Hickey JV. The clinical pratice of neurological and neurosurgical nursing. $4^{\text {th }}$ ed. Philadelphia: Lippincott; 1997. Stroke and other cerebrovascular diseases. p. 543-67.

(6) Silva IP. As relações de poder entre o adulto dependente e a mulher - cuidadora. [dissertação] São Paulo (SP): Pontifícia Universidade Católica de São Paulo; 1995.

(7) Andrade OG. Cuidado ao idoso com seqüela de acidente vascular cerebral: representações do cuidador familiar. [dissertação] Ribeirão Preto (SP): Escola de Enfermagem de Ribeirão Preto/USP; 1996.

(8) Souza RMC. Padrão de recuperação das vítimas de trauma crânio-encefálico aos 6 meses e 1 ano. [tese] São Paulo (SP): Programa Interunidades da Escola de Enfermagem e Escola de Enfermagem de Ribeirão Preto/USP; 1995.

(9) Smelzer SC, Bare BG. Brunner/Suddarth: tratado de enfermagem médico-cirúrgica. 7. ed. Rio de Janeiro: Guanabara Koogan, 1994. v. 4.

(10) Black JM, Matassarin-Jacobs E. Lucmann \& Sorensen - enfermagem médico-cirúrgica: uma abordagem psicofisiológica. 4 .ed. Rio de Janeiro: Guanabara Koogan,1996. v. 1.
(11) Ministério da Saúde. Secretaria de Assistência à Saúde. Conselho Nacional de Saúde. Programa Nacional de DST/AIDS. Diretrizes e normas regulamentadoras de pesquisa envolvendo seres humanos. Brasília; 1997.

(12) Perracini MR. Análise multidimensional de tarefas desempenhadas por cuidadores familiares de idosos de alta dependência. [dissertação] Campinas (SP): Faculdade de Educação da UNICAMP; 1994.

(13) Machado HB. Enfrentando a condição crônica de saúde após um acidente cerebral: um estudo de caso. [dissertação] Florianópolis (SC): Centro de Ciências da Saúde da UFSC; 1995.

(14) Faro ACM. Cuidar do lesado medular em casa: a vivência singular do cuidador familiar. [tese] São Paulo (SP): Escola de Enfermagem da USP; 1999.

(15) Mendes PMT. Cuidadores: heróis anônimos do cotidiano. [dissertação] São Paulo (SP): Pontifícia Universidade Católica de São Paulo; 1995.

(16) Williams A. What bothers caregivers of strocke victims? Jour Neurosc Nurs 1994; 26(3):155-61.

(17) Canam C, Acorn S. Quality of life for family caregivers of people with chronic health problems. Rehab Nurs 1999; 24(5):192-6.

(18) Elsen I, Marcon SS, Santos MRS, organizadores. O viver em família e sua interface com a saúde e a doença. Maringá: UEM; 2002.

(19) Lacerda MR. Metodologia para o cuidado domiciliar de enfermagem. In: Westephalen MEA, Carraro, TE, organizadores. Metodologia para a assistência de enfermagem: teorizações, modelos e subsídios para a prática. Goiânia: AB; 2001.
Cuidar da pessoa incapacitada por acidente vascular cerebral no domicílio: o fazer do cuidador familiar
Correspondência: Nara M. Oliveira

Rua José Gabriel, 359 Centro - ljuí CEP -98700-000 - RS

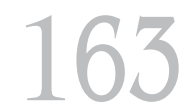

Rev Esc Enferm USP 2005; 39(2):154-63. 